\title{
Dural Venous Channels: Hidden in Plain Sight-Reassessment of an Under-Recognized Entity
}

\author{
(D) M. Shapiro, (D) K. Srivatanakul, (DE. Raz, (D). Litao, (D) E. Nossek, and DP.K. Nelson
}

\begin{abstract}
BACKGROUND AND PURPOSE: Tentorial sinus venous channels within the tentorium cerebelli connecting various cerebellar and supratentorial veins, as well as the basal vein, to adjacent venous sinuses are a well-recognized entity. Also well-known are "dural lakes" at the vertex. However, the presence of similar channels in the supratentorial dura, serving as recipients of the Labbe, superficial temporal, and lateral and medial parieto-occipital veins, among others, appears to be underappreciated. Also under-recognized is the possible role of these channels in the angioarchitecture of certain high-grade dural fistulas.
\end{abstract}

MATERIALS AND METHODS: A retrospective review of 100 consecutive angiographic studies was performed following identification of index cases to gather data on the angiographic and cross-sectional appearance, location, length, and other features. A review of 100 consecutive dural fistulas was also performed to identify those not directly involving a venous sinus.

RESULTS: Supratentorial dural venous channels were found in $26 \%$ of angiograms. They have the same appearance as those in the tentorium cerebelli, a flattened, ovalized morphology owing to their course between 2 layers of the dura, in contradistinction to a rounded cross-section of cortical and bridging veins. They are best appreciated on angiography and volumetric postcontrast T7weighted images. Ten dural fistulas not directly involving a venous sinus were identified, 6 tentorium cerebelli and 4 supratentorial.

CONCLUSIONS: Supratentorial dural venous channels are an under-recognized entity. They may play a role in the angioarchitecture of dural arteriovenous fistulas that appear to drain directly into a cortical vein. We propose "dural venous channel" as a unifying name for these structures.

V

ariation is the rule in all things venous. Cortical veins may be balanced or not (dominant Trolard, Labbe, superficial Sylvian arrangements), interconnected or not (Fig 1). Dural venous sinuses, likewise, are of variable size depending on how much blood they carry. The best-known example is the variation in dominance of left or right transverse/ sigmoid outflow. However, similar variations take place throughout the venous system. Multiple solutions exist for venous blood to exit the skull. ${ }^{1}$ Smaller jugular veins are frequently associated with correspondingly larger mastoid or condylar veins (Fig 2) or a larger cavernous sinus. Emissary and diploic veins can carry substantial volume, especially

Received March 27, 2020; accepted after revision May 18.

From the Departments of Radiology (M.S., E.R., P.K.N.), Neurology (M.S., M.L.), and Neurosurgery (E.N., P.K.N.), NYU School of Medicine, New York, New York; and Department of Neurosurgery (K.S.), Tokai University, Kanagawa, Japan.

Please address correspondence to Maksim Shapiro, MD, Bernard and Irene Schwartz Interventional Neuroradiology Section, NYU Langone Medical Center, 660 First Ave, 7th floor, New York, NY 10016; e-mail: neuroangio@neuroangio.org; @neuroangiol; @neuroangio

Indicates article with supplemental on-line photo.

http://dx.doi.org/10.3174/ajnr.A6647 when jugular and cavernous outflow routes are developmentally hypoplastic (Fig 2). ${ }^{2}$

From an embryologic perspective, dural sinuses form primarily during the second month of gestation from the "meninx primitiva" and continue to develop/mature throughout gestation and after birth. Discussion of these events is well-covered in multiple prior publications. ${ }^{2-5}$ One consequence of dural development is the potential for the entire dural cover to serve as a pathway for venous flow. The preference for main channels such as the superior sagittal, transverse, sigmoid, and straight sinuses is to form along the edges where the 2 apposed dural layers are separated, probably for hemodynamic reasons. However, the proximal superior sagittal sinus can run to the side of the falx, be duplicated, fenestrated, and so forth. In pathologic states, particularly arteriovenous shunts, the dura can participate extensively in drainage of arteriovenous fistulas, usually in a beneficial manner, because it provides additional routes for venous egress.

In terms of connection between cortical and dural systems, all brain surface veins must, at some point, cross the subdural space (named "bridging veins" in this location) to reach the dura. ${ }^{2}$ These bridging veins have been the subject of studies, especially concerning traumatic subdural hematomas and nonaccidental 

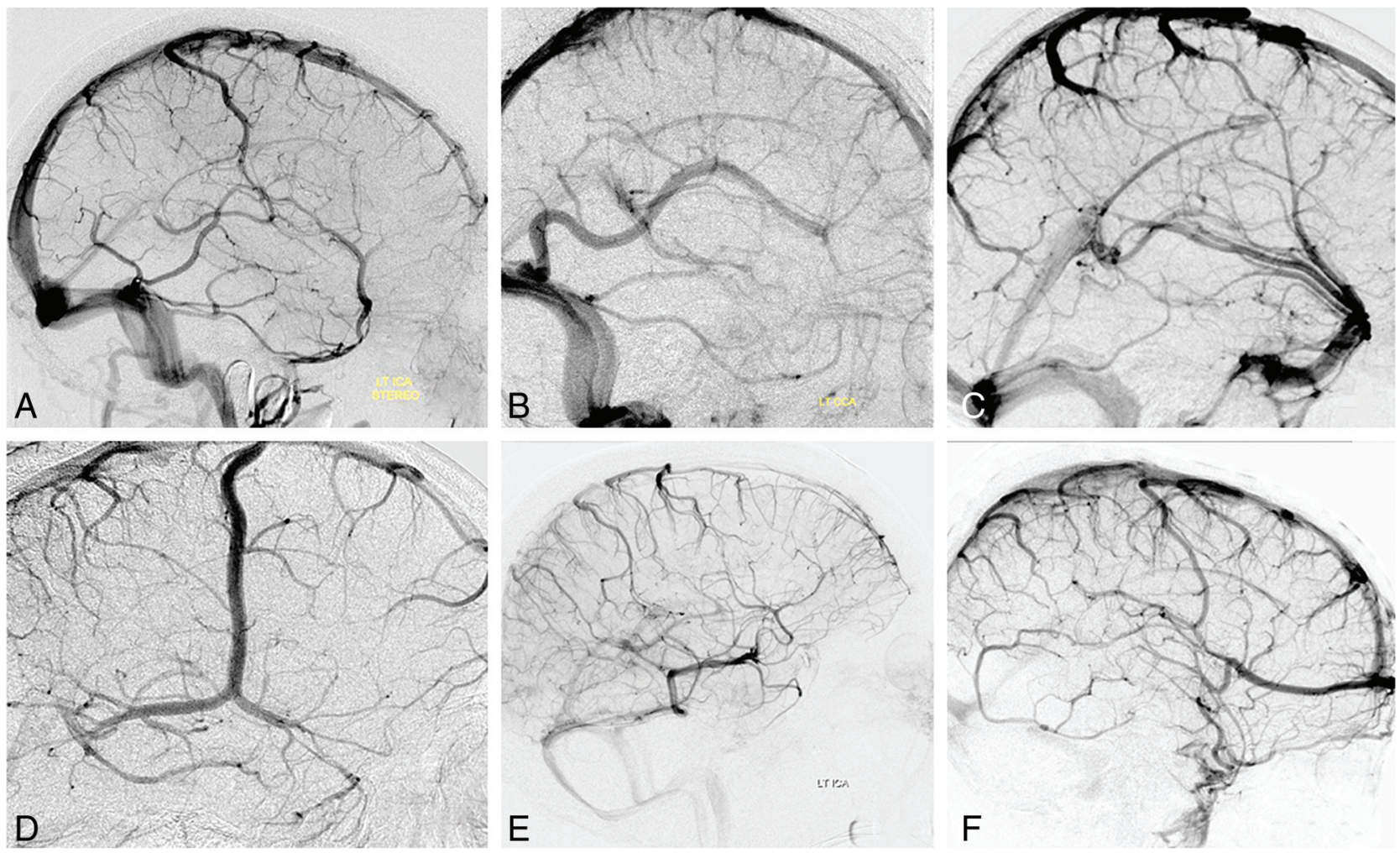

FIG 1. Illustrative variations of superficial venous drainage. $A$, Balanced pattern. $B$, Dominant Labbe. C, Dominant superficial Sylvian veins. $D$, Dominant Rolandic. E, Dominant basal vein with variant drainage. F, Dominant anterior frontal vein, a treacherous variation in cases of surgical sacrifice of a distal superior sagittal sinus.
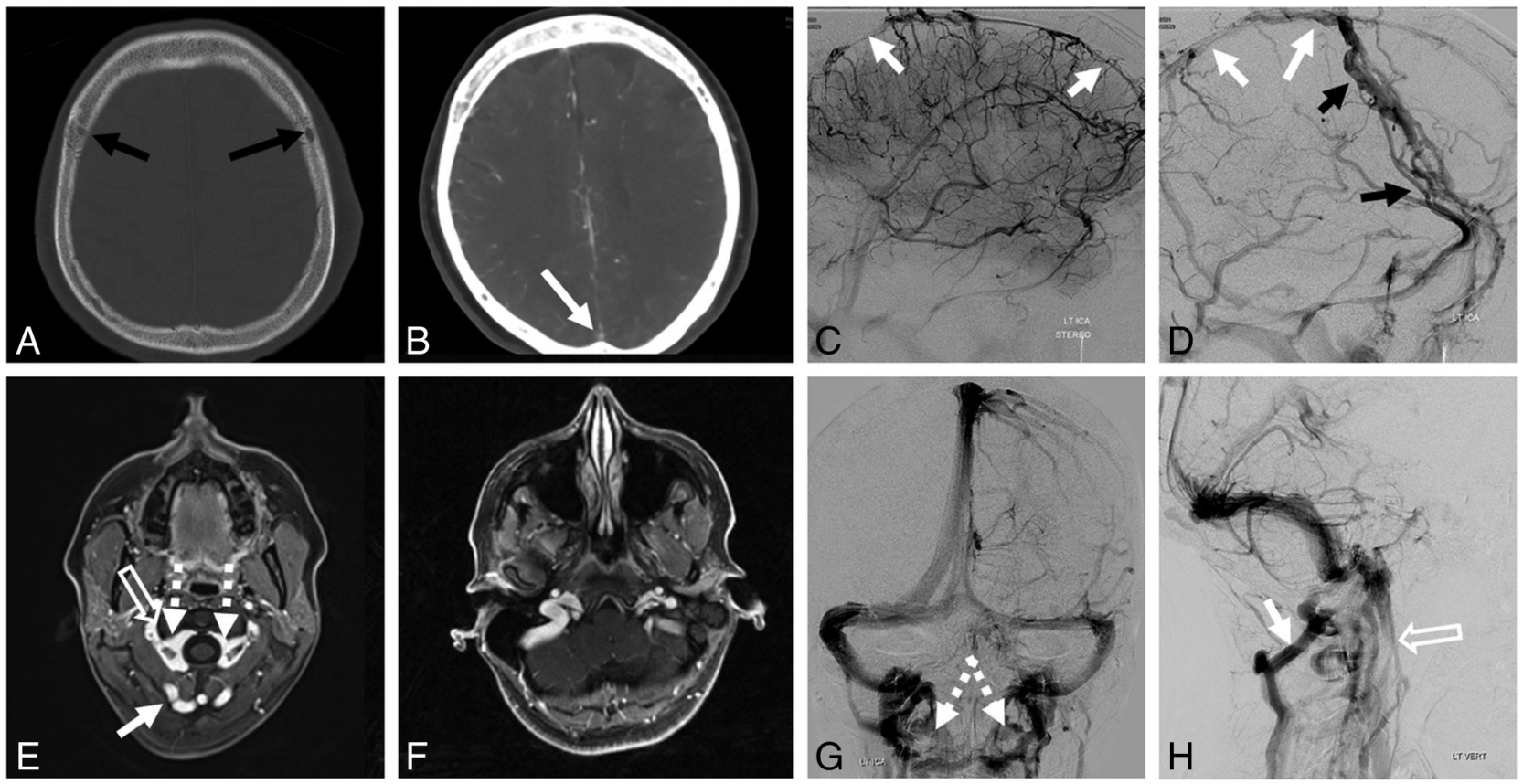

FIG 2. Variations of venous drainage. $A-D$, Hypoplastic superior sagittal sinus (white arrows) is associated with prominent diploic veins (black arrows). $E-H, C l$ lateral mass region stenoses of the jugular system (open arrows) are associated with compensatory prominence of condylar/suboccipital veins (white arrows), draining in large part into the vertebral venous plexus (dashed arrows). This configuration is further modified in nonrecumbent positions.

pediatric injuries. ${ }^{6,7}$ Most empty directly into venous sinuses. However, there are some important variations, such as wellknown dural "venous lakes," which present typically at the frontoparietal junction adjacent to the superior sagittal sinus. These lakes play an important angioarchitectural role in the rarebut-complex superior sagittal sinus dural fistulas and are a 
recognized surgical obstacle, for example during resection of parasagittal meningiomas. ${ }^{8}$

Also, very well-described are frequently seen venous channels in the tentorium cerebelli, collectively known as "tentorial sinuses." 9,10 These channels receive both supratentorial and infratentorial bridging veins as well as the basal vein, coursing with the tentorium toward a named venous sinus. Excellent descriptions (including morphologic subclassifications) of these channels can be found in multiple publications, emphasizing their surgical importance, because inadvertent injury during cutting of the tentorium may lead to venous infarction. ${ }^{9,10}$ Baltsavias et $\mathrm{al}^{2}{ }^{2}$ in addition to providing perhaps the most widely known illustration of these tentorial sinuses, emphasized their role in some dural fistulas, ${ }^{11-13}$ where arteriovenous communication appears to form within or immediately adjacent to such tentorial sinuses. Because the sinus acts as an immediate recipient of a cortical vein, these fistulas are strategically positioned to effect early and extensive cortical venous reflux, thus placing them into a higher risk category. $^{2,14-16}$

Existence of dural channels outside the tentorium cerebelli, principally associated with the Labbe venous group, was first angiographically shown, to our knowledge, by Huang et al., in $1984,{ }^{17}$ who described the dural channel as an "unusual superior extension of the dural sinus from the lateral sinus." It was subsequently shown by Srivatanakul et al, in 2013, ${ }^{18}$ termed "accessory epidural sinus" according to nomenclature by Lasjaunias et al, ${ }^{1}$ highlighting its surgical implications and possible association with a supratentorial dural fistula. Baltsavias et $\mathrm{al}^{2}$ and Koperna et $\mathrm{al}^{19}$ emphasized their association with the Labbe venous group. However, the importance of these findings seems to be underappreciated, and their recognition on cross-sectional imaging may be challenging. We have come across multiple examples of dural venous channels located in the supratentorial compartment, rather than in the tentorium cerebelli (Fig 3). While these do not appear to be nearly as common as those of tentorium cerebelli or the venous lakes, the same surgical and pathologic implications likely apply.

\section{MATERIALS AND METHODS}

Following the identification of several cases, we performed an NYU institutional review board-approved retrospective review of 100 consecutive angiograms to identify cases of supratentorial dural venous channels. The structure was defined as a flattened, biconvex dural venous channel, with a diameter that is larger in the plane of the dura and smaller in the plane perpendicular to it, connecting a cross-sectionally round cortical/bridging vein to a named sinus such as the superior sagittal, transverse, or sigmoid sinus. The main uncertainty is in defining the length of the channel because this impacts estimates of prevalence and clinical importance. Because we could identify no clinically relevant cutoff length, we arbitrarily defined it as clearly extending beyond the recipient venous sinus. Incomplete angiograms or cases obtained for evaluation of venous diseases were excluded. Channels in the tentorium cerebelli and venous lakes of the parasagittal dura or subjacent falx were excluded as well-known structures (though we believe these to be part of dural venous channel spectrum). We reviewed cross-sectional MR imaging and CT of

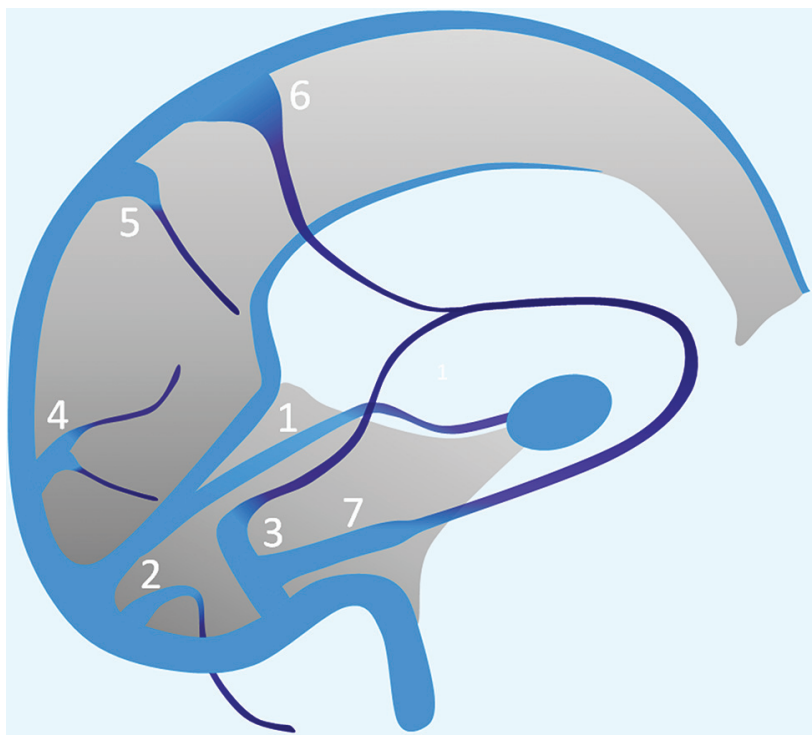

FIG 3. The variety of dural venous channels. Any part of the dura can be a venous channel, supra- or infratentorial. There is nothing particularly unique about a tentorial sinus except for the increased frequency of dural venous channels there. 1) Dural venous channel (tentorial sinus group) receiving the basal vein; 2) Dural venous channel (tentorial sinus group) receiving the inferior cerebellar vein; 3) Dural venous channel receiving the vein of Labbe; 4) Dural venous channel (falcine sinus group) receiving a parieto-occipital vein; 5) Dural venous channel (parietal) receiving either a medial or lateral parietal vein such as the vein of Trolard; 6) Dural venous channel (venous lake) receiving the Rolandic/Trolard group of veins; 7 ) Dural venous channel receiving the superficial Sylvian group of veins. Together with the Labbe dural channel ( 3 above), these drain into the sigmoid sinus.

\section{Supratentorial dural venous channel characteristics, based on} review of 100 consecutive angiograms

\begin{tabular}{lcc}
\hline & No. & $\%$ \\
\hline Patients with supratentorial dural venous channels & 26 & 26 \\
No. of supratentorial dural venous channels & 29 & 29 \\
Average dural venous channel length (mm) & 20 & \\
No. of dural venous channels on right side & 19 & 66 \\
Dural venous channel, female patients & 20 & 77 \\
Overall No. of females in angiographic sample $^{\text {Location of supratentorial dural venous channel }}{ }^{\mathrm{a}}$ & 63 & 63 \\
$\quad$ & 19 & 66 \\
$\quad$ Posterior temporal & 4 & 14 \\
$\quad$ Parietal & 6 & 21 \\
\hline Occipital
\end{tabular}

axcludes "dural venous lakes" and vertex falx cerebri channels.

angiographically identified cases, when available, for the corresponding appearance of dural venous channels.

A retrospective review of 100 consecutive dural fistula angiograms was performed to identify fistulas not primarily draining into a venous sinus segment, instead decompressing directly into cortical veins.

\section{RESULTS}

Of 100 consecutive adult angiograms (mean age, 58 years; 63 women), 26 cases contained 29 total dural channels. Details are listed in the Table, and examples are shown in Figs 4-7 and Online Figure. We recognized a few common elements: 

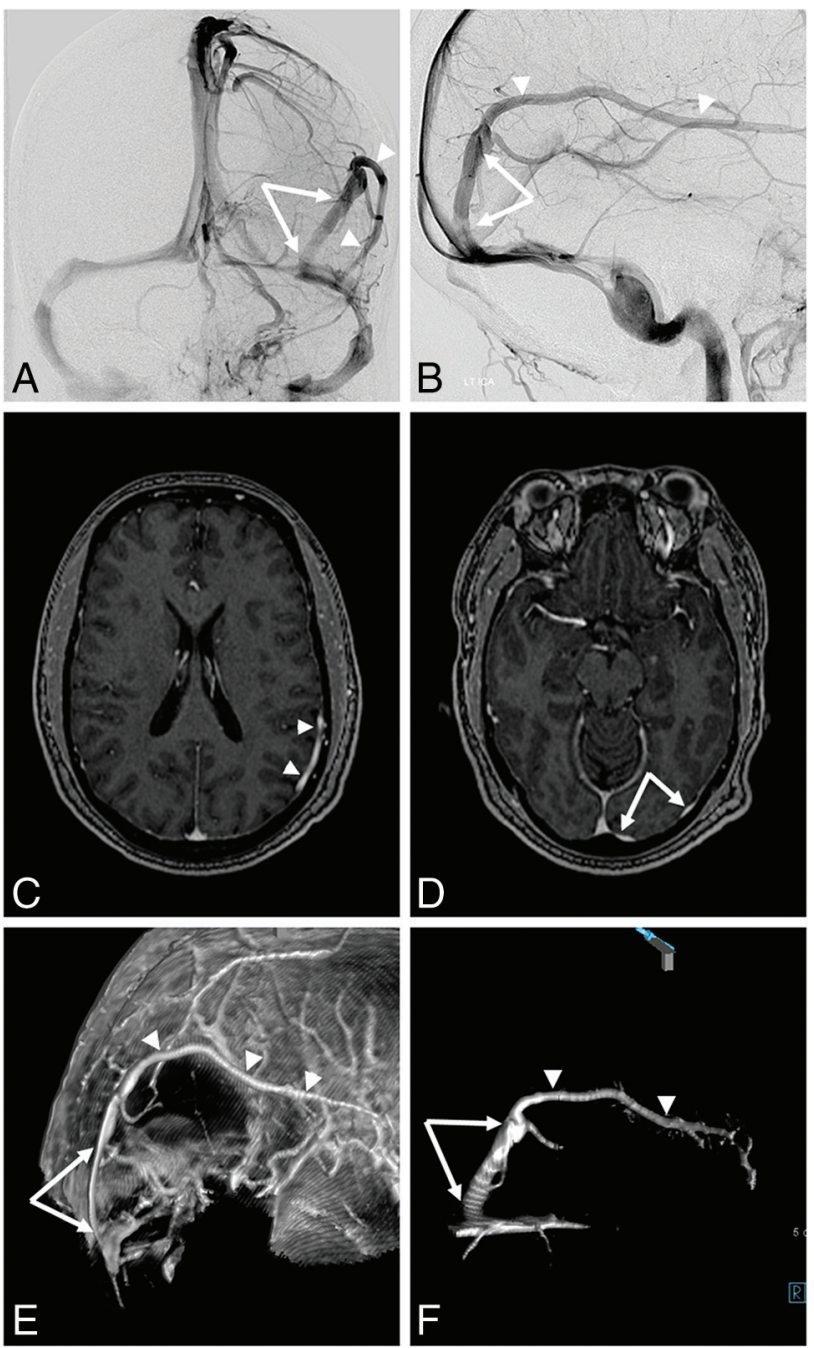

FIG 4. Typical dural venous channel (white arrows) draining a large vein of Labbe (white arrowheads). $A$ and $B$, Angiographic images. $C$ and $D$, Postcontrast $T$ axial volumetric source images. $E$ and $F$, Volume-rendered reconstructions of the above axial $\Pi 1$ post-contrast dataset.

1. The characteristic appearance, by morphologic definition, is a change from rounded morphology of a cortical/bridging vein to the flattened morphology of the dural venous channel. Not infrequently, this transition is associated with angulation or inflection as the bridging vein enters the dura (Figs 4-7 and On-line Figure).

2. Multiple cortical/bridging veins can drain into the same dural venous channel, sometimes visualized from separate carotid and vertebral injections (Figs 5-7 and On-line Figure).

3. Most channels seem to be located dorsally, draining posterior temporal, parietal, and occipital areas. The Trolard/Rolandic group frequently drains first into a falx cerebri or parasagittal convexity dural channel, which then empties into the superior sagittal sinus. These venous lakes are another example of a tentorial venous channel spectrum and seem to be particularly well-seen on vessel wall imaging (Fig 7).

4. Most channels are associated with large-caliber cortical/ bridging veins. We postulate that greater flow may lead to persistence of dural venous channels because the dura is formed from the meninx primitiva.
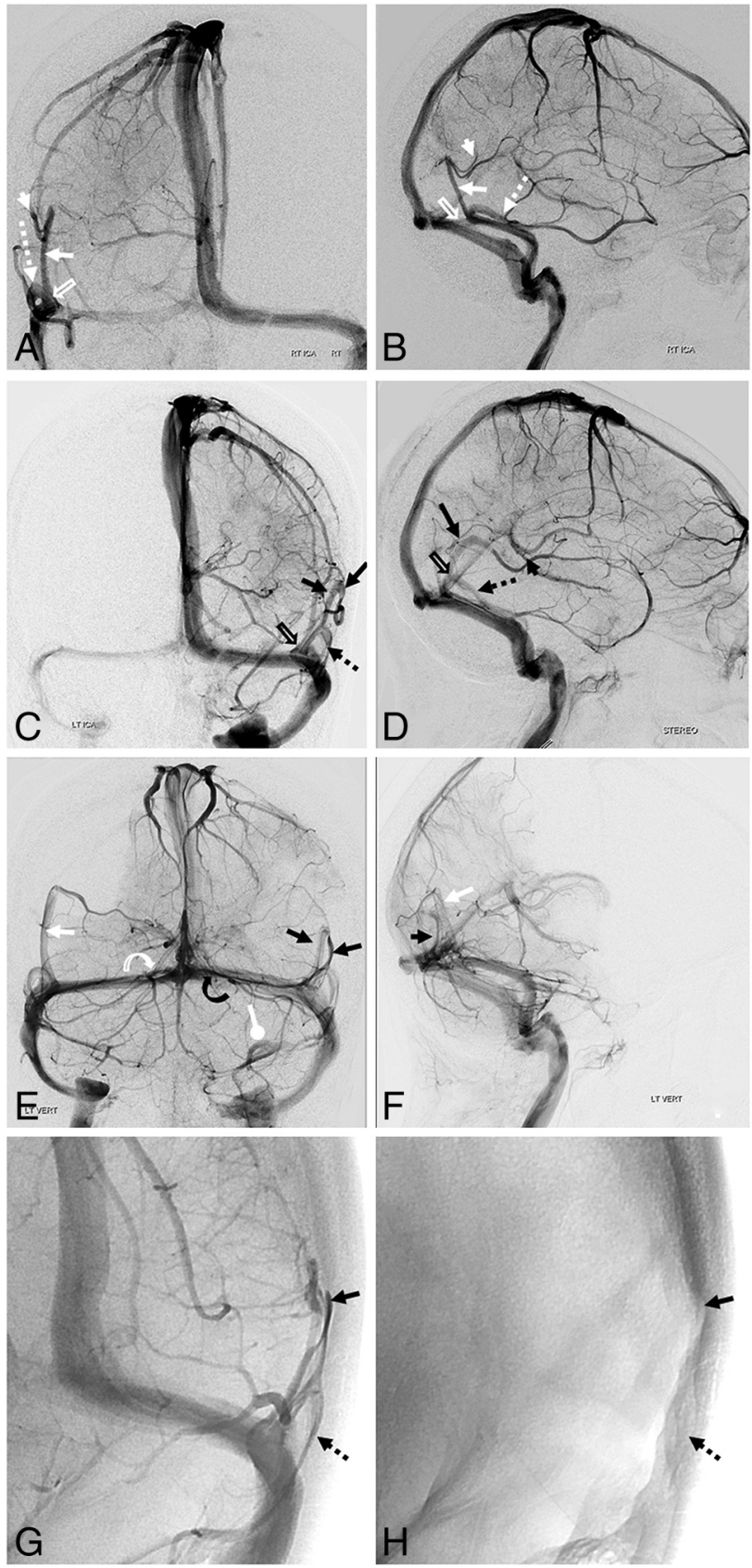

FIG 5. Mirror image of dural venous channels. Right ICA ( $A$ and $B)$, left ICA ( $C$ and $D$ ), and vertebral ( $E$ and $F$ ) injections. On the right, the posterior temporal (white arrowhead) vein drains into a dural venous channel (white arrow). The inferior temporal veins drain into a separate dural venous channel (dashed arrow). The 2 channels form a common dural channel (open arrow) draining into the proximal transverse sinus. A mirror image appearance is seen on the left. $C$ and $D$, Corresponding black arrows. $E$ and $F$, Vertebral injection opacifies the same dural venous channels (white and black arrows), collecting posterior temporal and occipital veins. Also seen are several dural venous channels in the tentorium cerebelli, also known as tentorial sinuses (curved arrows, ballpoint arrow). $G$ and $H$, Left anterior oblique views of the left ICA injection profile dural venous channels seen in $C$ and $D$. Notice the flattened appearance and location of channels lateral to parenchymal veins and corresponding indentations on the inner surface of skull due to flow-related remodeling. 


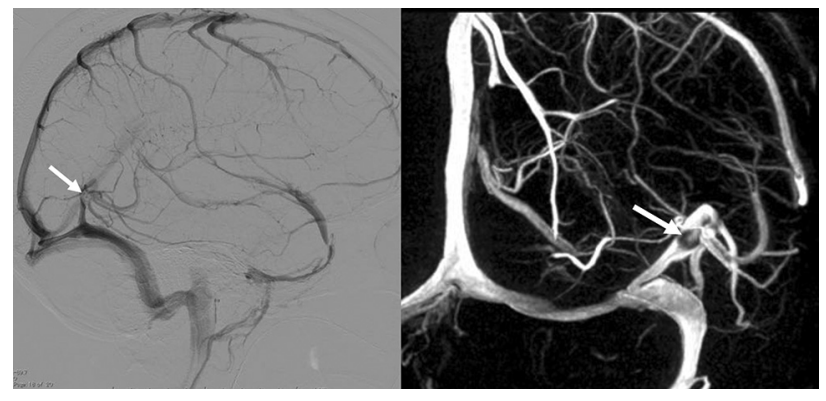

FIG 6. Dural venous channel with an associated arachnoid granulation (arrows) - another characteristic of a dural structure.
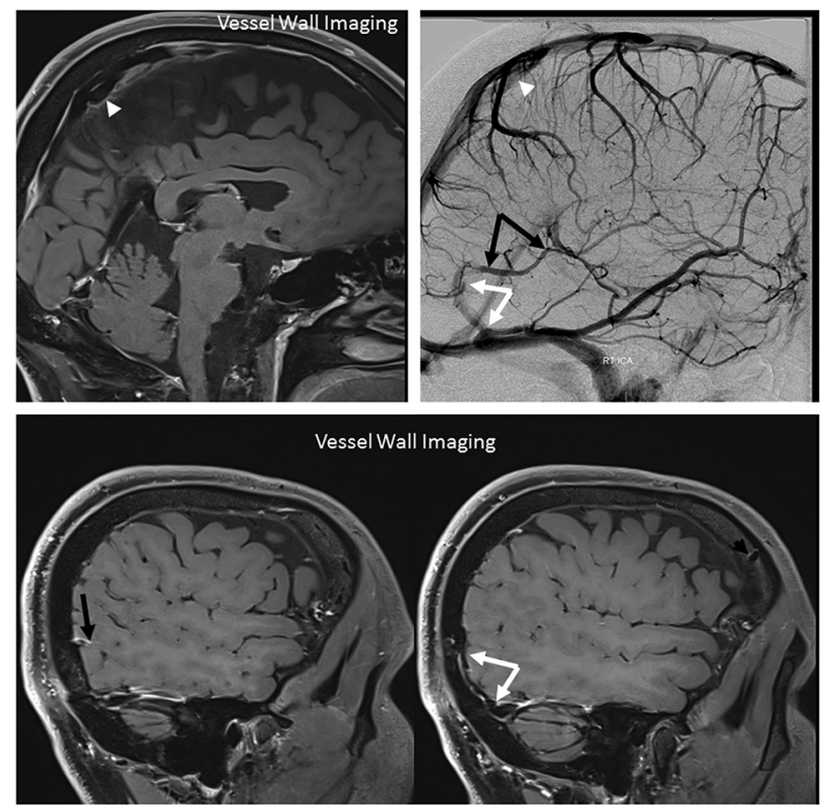

FIG 7. Vessel wall imaging of dural venous channels in the falx cerebri (white arrowheads), collecting the Trolard group, and lateral tentorium (white arrows), collecting the Labbe group (black arrows).

5. An oblique angiographic view parallel to the dural venous segment is best for depicting the flattened nature of the channel, sometimes scalloping the adjacent inner table (Fig 5).

6. Among noninvasive options, volumetric postcontrast T1weighted images are best for appreciating the dural nature of these channels and for generating optimal reconstructions. Nonvolumetric sequences seem to either lack resolution except in obvious cases or be degraded by various flow artifacts. Postcontrast MR venograms can be diagnostic as well; however, because one of MR imaging's advantages over angiography is the ability to optimally show the relationship between dural channels and adjacent brain and skull structures, subtracted images may, in fact, be detrimental in these cases. Vessel wall imaging appears to be very promising. Standard noncontrast techniques seem decidedly inferior.

Our retrospective review of the last consecutive 100 dural fistula angiograms performed at NYU identified 10 dural fistulas (average age, 58 years; 5 women; all Cognard type IV/Borden
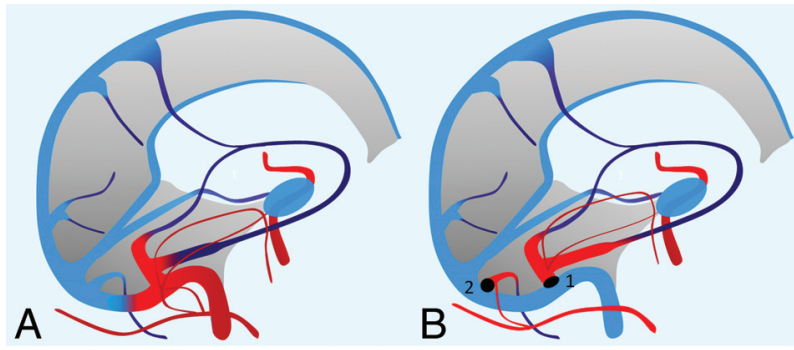

FIG 8. $A$, Classic dural fistula with an arteriovenous connection directly involving a dural (sigmoid in this case) sinus. $B$, Dural fistula with an arteriovenous connection involving a dural venous channel segment of the Labbe (1) and posterior cerebellar (2) veins. Thrombosis or restriction of antegrade outflow (black circles) into a draining sinus results in retrograde congestion of the cortical venous system. These seemingly "direct" fistulas draining exclusively into a cortical vein are proposed to primarily involve a dural venous channel, explaining the seemingly random dural location of these fistulas.

type III) draining primarily into a cortical vein, presumably via a dural venous channel segment, instead of involving the wall of a venous sinus (Figs 8 and 9). Six were fistulas of the tentorium cerebelli, 4 fistulas were supratentorial, and 3 presented with hemorrhage: 1 infratentorial, 2 supratentorial.

\section{DISCUSSION}

It stands to reason, including embryologic considerations, that dural venous channels can and should exist in dural covers other than tentorium cerebelli. ${ }^{5}$ Their presence in association with the vein of Labbe has been described. ${ }^{2,19}$ What is underappreciated is the high frequency with which these supratentorial channels are encountered, and their role in draining veins other than the Labbe group, particularly the parieto-occipital region draining into the proximal superior sagittal or transverse sinuses. Srivatanakul et $\mathrm{al}^{18}$ estimated a prevalence at $10 \%$. The number here ( $26 \%$ of patients) is substantially higher; differences might be related to interobserver variability, angiographic methodology, and equipment and suggest the need for additional investigations. A higher percentage incidence in women may be analyzed in a larger sample. Predilection for occurrence on the right side may be related to the well-known overall tendency for right jugular dominance, indirectly supporting the embryologic notion that more flow favors dural channel formation.

A number of articles on tentorial sinus venous channels focused on their relatively frequent presence $(>80 \%$ of the time $e^{9,10}$ ) and surgical importance; inadvertent injury of these during cutting of the tentorium risks venous infarction., ${ }^{9,10}$ To the extent that operations on the Labbe or parieto-occipital region are relatively uncommon, the incidence of inadvertent injury to regional dural venous channels may be low; however, recognition of venous injury as a cause of postoperative venous infarction might be difficult if the existence of these dural channels is not appreciated a priori.

Also underappreciated is the possible role of these channels in dural fistulas that do not primarily involve a major sinus. While most fistulas do primarily involve a sinus, ${ }^{15,16}$ a substantial minority appear to be located either on the tentorium 

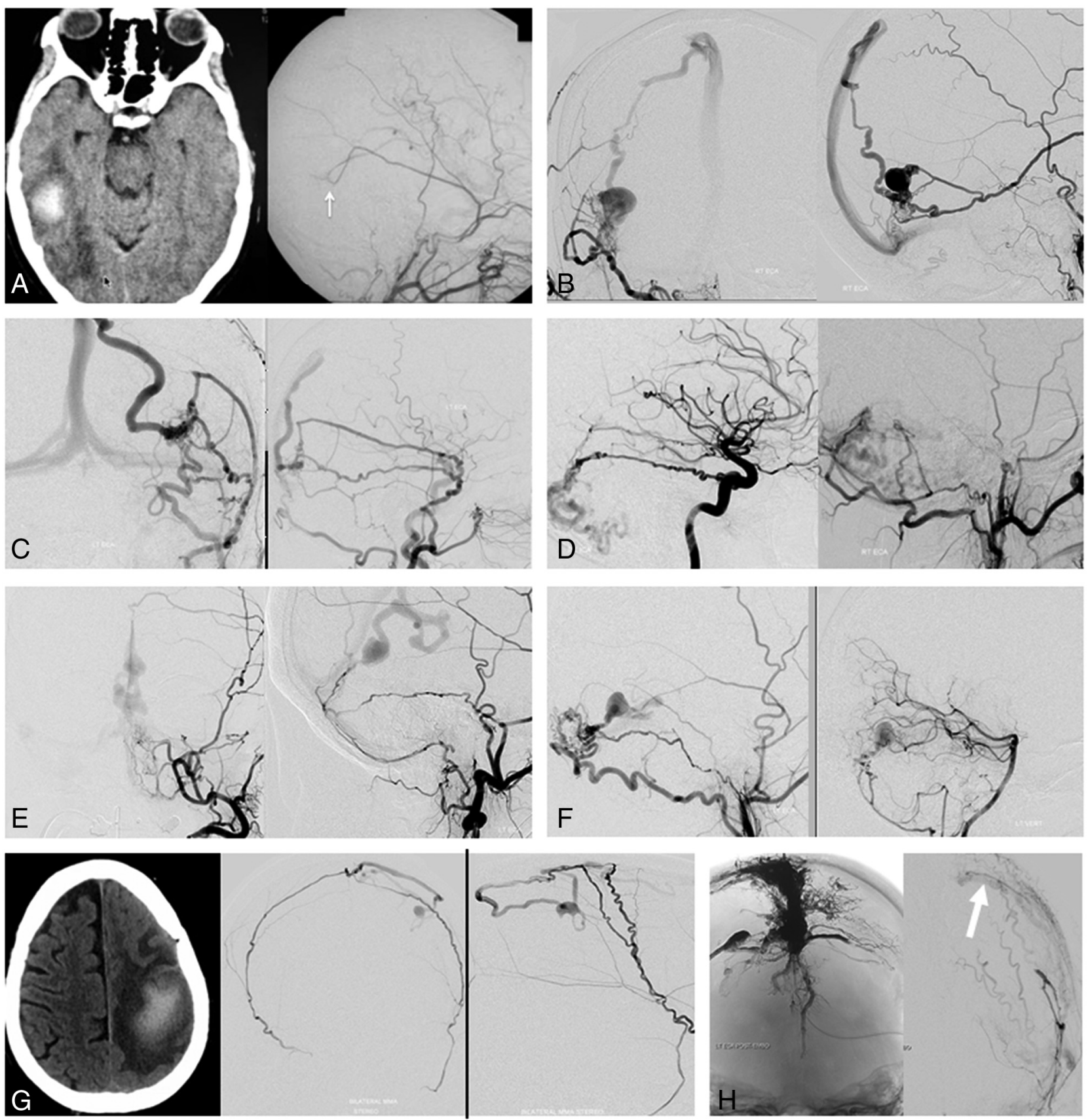

FIG 9. Dural fistulas draining directly into a cortical vein instead of a sinus, which may illustrate the concept of a dural venous channel fistula shown in Fig 8. A, Venous congestion hemorrhage due to a fistula (arrow) between the middle meningeal artery and the vein of Labbe. $B$ and $C$, Fistulas just above the transverse sinus, with typical arterial supply and drainage into the parietal veins. $D-F$, Tentorial cerebelli fistulas congesting various cerebellar veins. These can be found anywhere on the tentorium, including the midline/vermian region (E). $G, A$ small parasagittal fistula between the artery of the superior sagittal sinus supplied by both middle meningeal arteries and the vein of Trolard. Despite the small fistula size, the resulting Trolard congestion precipitated a large venous infarct. $H$, Complex vertex/frontoparietal dural fistula. Despite the presence of extensive Onyx (Covidien) and $n$-BCA embolic material in the sinus and adjacent venous lakes, there remains a parasagittal fistula between the middle meningeal artery and the Rolandic vein (white arrow). The fistula is clearly lateral to the sinus, illustrating the shunt location within the parasagittal venous lake. Multiple similar fistulas in this case have already been closed at this stage.

cerebelli ${ }^{11-13}$ or near a sinus but not primarily draining into it; instead, drainage proceeds directly into a cortical vein. By definition, these latter ones are of high Borden/Cognard types. ${ }^{14-16}$ Baltsavias et $\mathrm{al}^{2}$ refer to these as shunts of the bridging veins. ${ }^{14}$ It is difficult to imagine how a fistula not directly related to a sinus would gain access to a bridging or cortical vein unless that vein was a priori associated with a dural segment before subsequent fistula formation at that segment. A fistula adjacent to or draining into a dural venous channel is the most likely explanation (Fig 8). This was postulated and shown by Srivatanakul et $\mathrm{al}^{18}$ and suggested by Baltsavias et al. ${ }^{14}$ In our retrospective review of 100 consecutive dural arteriovenous fistulas, we 
identified 10 dural venous channel fistulas, 6 of the tentorium cerebelli and 4 supratentorial (Fig 9 and Table). Despite their high grade, most tend to be of relatively uncomplicated angioarchitecture, with a limited number of arteries converging on a single-hole fistula draining into a cortical vein. If transarterial access is not possible, a transvenous approach or surgical disconnection of the bridging vein from the dura is a feasible alternative. $^{18}$

\section{Limitations}

The main limitation is the retrospective, observational nature of this study. Not all angiographic cases had corresponding MR imaging or CT studies to investigate relative sensitivities, specificities, and so forth. A prospective analysis of multiple imaging modalities would be useful for many reasons, including educational ones for the cross-sectional imaging community. Another limitation is lack of correlation between the imaging appearance and direct visual inspection, either during an operation or postmortem examination. Also limiting is a lack of illustrative cases of venous infarction resulting from surgical injury to dural venous sinuses in our cohort.

\section{CONCLUSIONS}

Supratentorial dural venous sinus channels seem to be an underrecognized entity. They may play a role in some high-grade dural fistulas.

Disclosures: Kittipong Srivatanakul—UNRELATED: Payment for Lectures Including Service on Speakers Bureaus: honorarium for anatomy educational course, Comments: Part of the idea for this article was included in the lectures given in an anatomy educational course held in NYU Langone Health in November 2019. I was paid an honorarium for the lectures (payment not received yet). Eytan RazUNRELATED: Expert Testimony: various law firms; Royalties: Springer; Travel/ Accommodations/Meeting Expenses Unrelated to Activities Listed: MicroVention.

\section{REFERENCES}

1. Lasjaunias PL, Berenstein A, terBrugge KG. Surgical Neuroangiography. Springer-Verlag; 2001

2. Baltsavias G, Parthasarathi V, Aydin E, et al. Cranial dural arteriovenous shunts, Part 1: anatomy and embryology of the bridging and emissary veins. Neurosurg Rev 2015;38:253-63; Discussion 26-54 CrossRef Medline

3. Raybaud C. Normal and abnormal embryology and development of the intracranial vascular system. Neurosurg Clin N Am 2010; 21:399-426 CrossRef Medline
4. Padget $\mathrm{DH}$. The cranial venous system in man in reference to development, adult configuration, and relation to the arteries. $\mathrm{Am} \mathrm{J}$ Anat 1956;98:307-55 CrossRef Medline

5. Okudera T, Huang YP, Ohta T, et al. Development of posterior fossa dural sinuses, emissary veins, and jugular bulb: morphological and radiologic study. AJNR Am J Neuroradiol 1994;15:1871-83 Medline

6. Maxeiner $H$. Detection of ruptured cerebral bridging veins at autopsy. Forensic Sci Int 1997;89:103-10 CrossRef Medline

7. Rambaud C. Bridging veins and autopsy findings in abusive head trauma. Pediatr Radiol 2015;45:1126-31 CrossRef Medline

8. DiMeco F, Li KW, Casali C, et al. Meningiomas invading the superior sagittal sinus: surgical experience in 108 cases. Neurosurgery 2008;62:1124-35 CrossRef Medline

9. Matsushima T, Suzuki SO, Fukui M, et al. Microsurgical anatomy of the tentorial sinuses. J Neurosurg 1989;71:923-28 CrossRef Medline

10. Muthukumar N, Palaniappan P. Tentorial venous sinuses: an anatomic study. Neurosurgery 1998;42:363-71 CrossRef Medline

11. Wajnberg E, Spilberg G, Rezende MT, et al; Association of Rothschild Foundation Alumni (ARFA). Endovascular treatment of tentorial dural arteriovenous fistulae. Interv Neuroradiol 2012;18:60-68 CrossRef Medline

12. Byrne JV, Garcia M. Tentorial dural fistulas: endovascular management and description of the medial dural-tentorial branch of the superior cerebellar artery. AJNR Am J Neuroradiol 2013;34:17981804 CrossRef Medline

13. Osada $\mathrm{T}$, Krings $\mathrm{T}$. Intracranial dural arteriovenous fistulas with pial arterial supply. Neurosurgery 2019;84:104-15 CrossRef Medline

14. Baltsavias G, Kumar R, Avinash KM, et al. Cranial dural arteriovenous shunts, Part 2: the shunts of the bridging veins and leptomeningeal venous drainage. Neurosurg Rev 2015;38:265-71; discussion 272 CrossRef Medline

15. Borden JA, Wu JK, Shucart WA. A proposed classification for spinal and cranial dural arteriovenous fistulous malformations and implications for treatment. J Neurosurg 1995;82:166-79 CrossRef Medline

16. Cognard C, Gobin YP, Pierot L, et al. Cerebral dural arteriovenous fistulas: clinical and angiographic correlation with a revised classification of venous drainage. Radiology 1995;194:671-80 CrossRef Medline

17. Huang YP, Okudera T, Ohta T, et al. Anatomic Variations of the dural venous sinuses. In: Kapp JP, Schmidek HH, eds. The Cerebral Venous System and Its Disorders. Orlando: Grune \& Stratton; 1984:109-168

18. Srivatanakul K, Songsaeng D, Salliou G. Accessory epidural venous sinuses: angiographic characteristics, embryology, and clinical considerations. In: Proceedings of the Annual Meeting of the Japanese Society of Neuroradiology, Kokura, Japan. February 15-16, 2013

19. Koperna T, Tschabitscher M, Knosp E. The termination of the vein of "Labbe" and its microsurgical significance. Acta Neurochir (Wien) 1992;118:172-75 CrossRef Medline 